EXTENDED REPORT

\title{
Deposition of silicone oil droplets in the residual anterior lens capsule after vitrectomy and lensectomy in rabbits
}

\author{
T Miyamoto, S Saika, A Yamanaka, Y Okada, Y Ohnishi
}

Br J Ophthalmol 2004;88:703-707. doi: 10.1136/bjo.2003.021113

See end of article for authors' affiliations

....................

Correspondence to: T Miyamoto, M.D., Department of Ophthalmology, Wakayama Medical University, 811-1, Kimiidera,

Wakayama-city,

Wakayama, 641-0012,

Japan; tmiyam@

wakayama-med.ac.jp

Accepted 1 August 2003

\begin{abstract}
Aim: To examine the histology of preserved anterior lens capsule in vitrectomised and lensectomised rabbit eyes with and without silicone oil tamponade.

Methods: Forty adult Japanese albino rabbits received two port vitrectomy and lensectomy with or without silicone oil tamponade in one eye under both general and topical anaesthesia. Anterior lens capsule was preserved during operation. After healing intervals residual anterior capsule was histologically observed under light or electron microscopy.

Results: Immediately after operation, cuboidal lens epithelial cells were observed on the posterior surface of the preserved anterior capsule. During healing intervals in eyes with or without silicone oil tamponade, regenerated lens structure of Sommerring's ring and fibrous tissue formed in the peripheral and central areas of the residual capsule, respectively. Ultrastructural observation revealed the presence of many vacuoles amid matrix accumulation on the posterior capsular surface, suggesting the deposition of emulsified silicone oil droplets.

Conclusion: Lens epithelial cells produce regenerated lenticular structure and fibrous tissue on the residual capsule following vitrectomy and lensectomy in rabbits. Silicone oil droplets formed by its emulsification deposit in extracellular matrix accumulated on the posterior surface of the anterior capsule. Emulsified silicone may potentially enhance opacification of residual anterior capsule following pars plana vitrectomy by silicone oil deposition and subsequent activation of lens epithelial cells.
\end{abstract}

in the anterior chamber angle, leading to the development of secondary glaucoma. ${ }^{21-23}$ We have previously reported the presence of many vacuoles, which were presumed to be emulsified oil, in extracellular matrix accumulation in human healing anterior lens capsule following PPL, vitrectomy, and silicone oil tamponade in the treatment of proliferative vitreoretinopathy. ${ }^{24}$ However, such human specimens might not be enough to evaluate the exact effect of silicone oil on the histology of residual lens capsule after PPL. In the present study, we examine the histology of residual anterior capsule following lensectomy and vitrectomy with or without silicone oil tamponade in rabbits by using light and electron microscopy.

\section{MATERIALS AND METHODS}

\section{Surgical procedure in rabbits}

Forty adult Japanese albino rabbits (2.0-2.2 kg body weight) were used, under both general and topical anaesthesia with intramuscular injection of ketamin hydrochloride and xylazine, and oxybuprocaine eyedrops as previously reported..$^{25}$ Scleral incision was made at two points $1.0 \mathrm{~mm}$ apart from limbus, and then PPL and vitrectomy were performed using the 2 port system under infusion of balanced salt solution (BSS plus, Alcon, Fort Worth, TX, USA). Anterior capsule was preserved and posterior capsule was excised in one eye of each animal. Lens epithelial cells on the inner surface of the anterior capsule were not aspirated. The vitreous cavity in 20 eyes of 20 animals was filled with the irrigation solution, and that of the other 20 eyes was tamponaded with liquid silicone oil following fluid-air exchange technique. Scleral wounds were sutured and an antibiotic solution was administered subconjunctivally. After a specific healing interval of 2, 3, 4 weeks, and 12 months, the animals were sacrificed with an

Abbreviations: PEA, phacoemulsification and aspiration; PPL, pars plana lensectomy. 

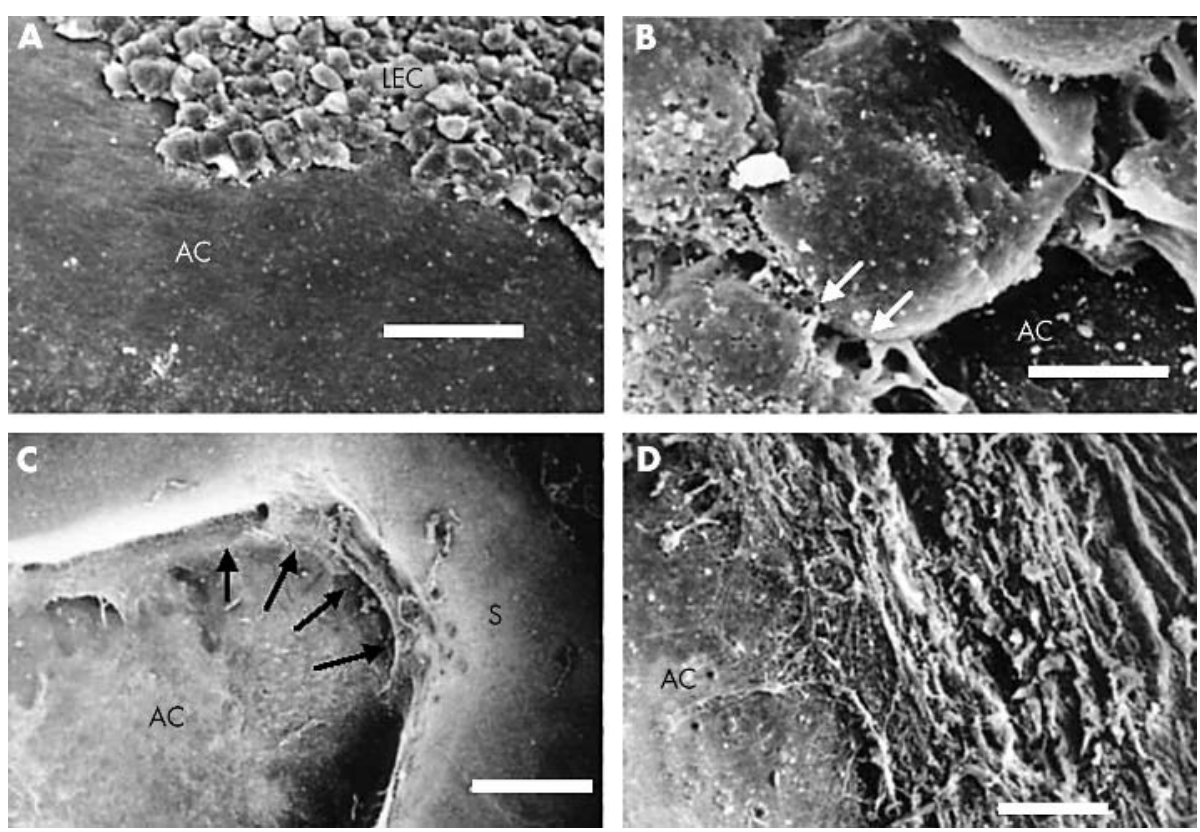

intravenous overdose of pentobarbital sodium. Each globe was enucleated and processed for histology as described below.

\section{Scanning electron microscopy}

Six globes excised at weeks 2 and 4 were fixed in $2.0 \%$ glutaraldehyde in $0.1 \mathrm{M}$ phosphate buffer for 24 hours at $4^{\circ} \mathrm{C}$. After hemisectioning the globe, the anterior segment of each globe was observed using the Miyake-Apple View ${ }^{26}$ after preparation for scanning electron microscopic examination-
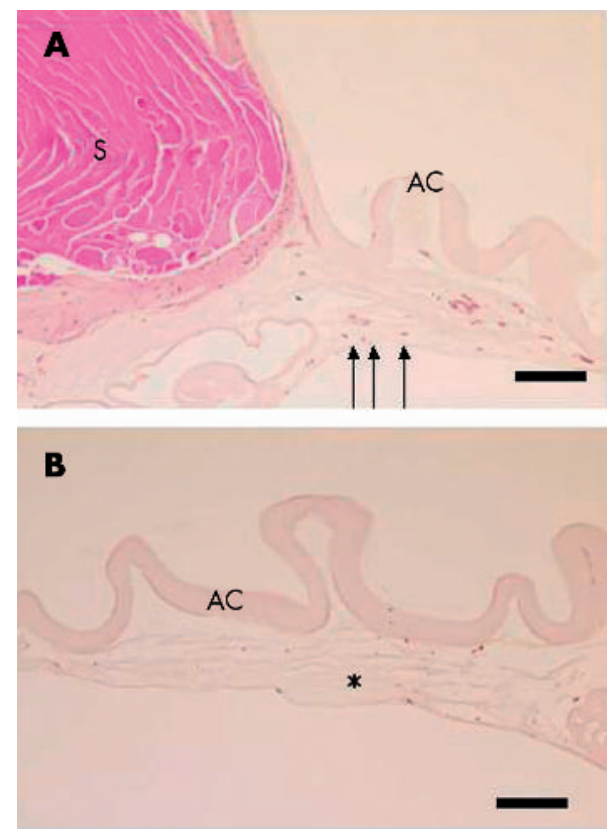

Figure 2 Histology with haematoxylin and eosin staining of a residual capsular structure at week 4 . (A) Regenerated lenticular structure of Sommerring's ring (S) is observed in the peripheral region. Arrow indicates the area of adhesion of anterior capsule (AC) and the peripheral edge of the equatorial capsule. (B) The central area of the posterior surface of the remaining anterior capsule $(A C)$ is covered with accumulation of fibrous extracellular matrix structure (asterisk) containing cells. Bar: $40 \mu \mathrm{m}$. that is, dehydration through an ethanol series, critical point drying, and cold coating by an ion spatter. ${ }^{27}$

\section{Light microscopy and immunohistochemistry}

Globes obtained at weeks 3 and 4 were embedded in OCT compound or paraffin following a 48 hour fixation in $2.0 \%$ paraformaldehyde in $0.1 \mathrm{M}$ phosphate buffer and dehydration. Cryosections $(8 \mu \mathrm{m}$ thick) or paraffin sections $(5 \mu \mathrm{m}$ thick) were processed for haematoxylin and eosin (HE) staining or indirect immunohistochemistry as previously reported. ${ }^{28}$ Antibodies used in this study are listed in table 1.

\section{Transmission electron miscroscopy}

Four globes excised at months 1 and 12 were fixed in $2.0 \%$ glutaraldehyde in $0.1 \mathrm{M}$ phosphate buffer for 24 hours at $4{ }^{\circ} \mathrm{C}$. Residual lens capsule was then removed and post fixed in $1.0 \%$ osmium tetroxide for 2 hours. Following dehydration through a graded ethanol series, specimens were embedded in Epon 812 mixture (Quetol 812, Nissin EM, Tokyo, Japan). Ultrathin sections were electron stained with uranyl acetate and lead citrate, and observed under transmission electron microscopy.

Table 1 Primary antibodies used for immunohistochemistry

\begin{tabular}{llll}
\hline Antibody & Animal & Dilution & Source \\
\hline Anti-type I collagen & Goat & X200 in PBS Fuji Yakuhin Kogyo† \\
Anti-type I collagen & Goat & X200 in PBS Southern Biotechnologył \\
$\begin{array}{l}\text { Anti-type III collagen } \\
\text { Anti-type III collagen }\end{array}$ & Goat & X200 in PBS Fuji Yakuhin Kogyo \\
$\begin{array}{l}\text { Anti-type IV collagen } \\
\text { Anti-type IV collagen }\end{array}$ & Goat & X200 in PBS Southern Biotechnology \\
$\begin{array}{l}\text { Anti-type V collagen } \\
\text { Anti-cellular fibronectin Goat }\end{array}$ & X200 in PBS Southern Biotechnology \\
$\begin{array}{l}\text { Anti-osteopontin } \\
\text { Goat }\end{array}$ & X200 in PBS Southern Biotechnology PBS Santa Cruz \\
Anti- $\alpha$ smooth & Mouse & X200 in PBS Sigma \\
muscle actin & & & \\
\hline
\end{tabular}

${ }^{*}$ Mouse monoclonal.

†Toyama, Japan.

$\ddagger$ Birmingham, AL, USA.

§Santa Cruz, CA, USA.

Saint Louis, MO, USA. 

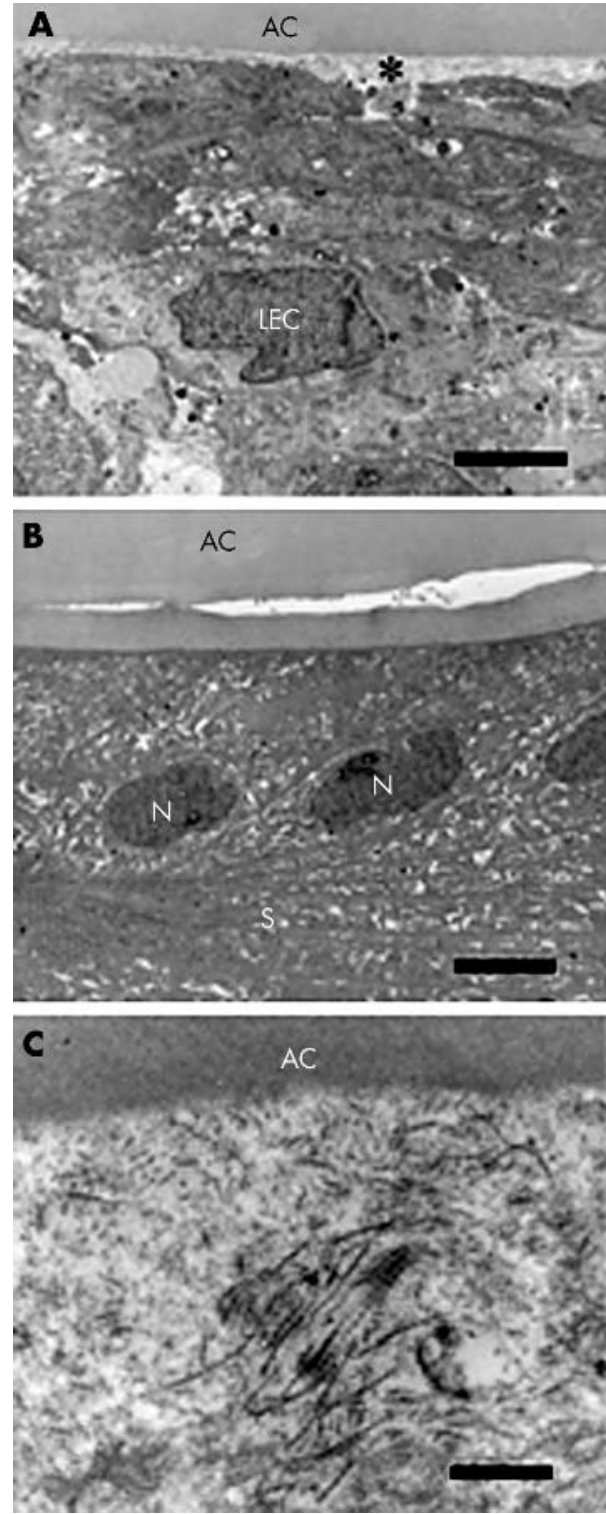

Figure 3 Transmission electron microscopy of residual capsular tissue after PPL and vitrectomy at week 4. (A) The central area of the posterior surface of the remaining anterior capsule $(A C)$ is covered with accumulation of fibrous extracellular matrix structure (asterisk) containing fibroblast like presumed lens epithelial cells. (B) Regenerated lenticular structure of Sommerring's ring $(S)$ is observed in the peripheral region. $\mathrm{N}$ indicates the nuclei of fibre differentiating cells. (C) A higher magnification picture of the asterisk area in frame $A$ shows the presence of banded matrix fibres of collagen beneath the anterior capsule. Bar: $3 \mu \mathrm{m}$ (A); $4 \mu \mathrm{m}$ (B); $0.5 \mu \mathrm{m}$ (C).

\section{RESULTS}

\section{Light and electron microscopy of healing capsule without silicone oil tamponade}

Scanning electron microscopy showed cuboidal epithelial cells lining the inner surface of the anterior capsule immediately after operation (fig $\mathrm{lA}$ and B). The edge of the capsular bag was found to adhere to the peripheral area of the posterior surface of the anterior capsule, forming the regenerated lenticular structure of Somerring's ring (fig lC). The central area of the posterior surface of the remaining anterior capsule was covered with fibrous connective tissue (fig 1D). Haematoxylin and eosin staining revealed similar findings as suggested by scanning electron microscopy. In healing capsular tissue, the capsular bag was found to adhere
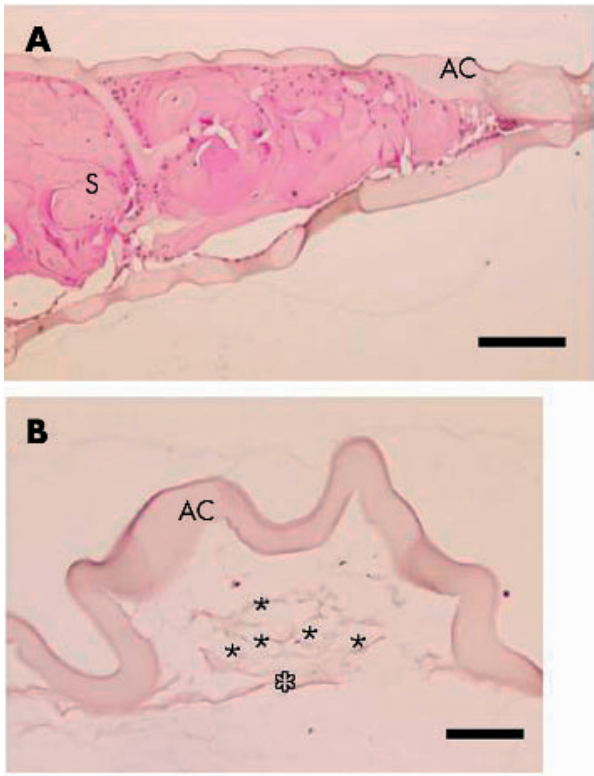

Figure 4 Histology with haematoxylin and eosin staining of a residual capsular structure in a silicone oil tamponaded eye at week 4. (A) Regenerated lenticular structure of Sommerring's ring $(S)$ is observed in the peripheral region. (B) The central area of the posterior surface of the remaining anterior capsule $(\mathrm{AC})$ is covered with an accumulation of fibrous extracellular matrix structure (open asterisk) containing cells. Many vacuoles can be seen amid the matrix (asterisks). Bar: $40 \mu \mathrm{m}$.

to the posterior surface of the anterior capsule, forming the regenerated lenticular structure of Sommerring's ring (fig 2A). The central area of the posterior surface of the remaining anterior capsule was covered with fibrous connective tissue (fig 2B). Transmission electron microscopy in specimens at weeks 2 and 4 showed the presence of lens epithelial cells beneath the anterior capsule and regenerated lenticular structure in the peripheral area. Lens cells in the central area of the inner surface of the anterior capsular were elongated and fibroblast like (fig 3A), while regenerated lens fibres were seen in Sommerring's ring in the peripheral area (fig 3B). Extracellular matrix was found to be accumulated amid the lens cells with a fibroblastic appearance. An observation at a higher magnification revealed the presence

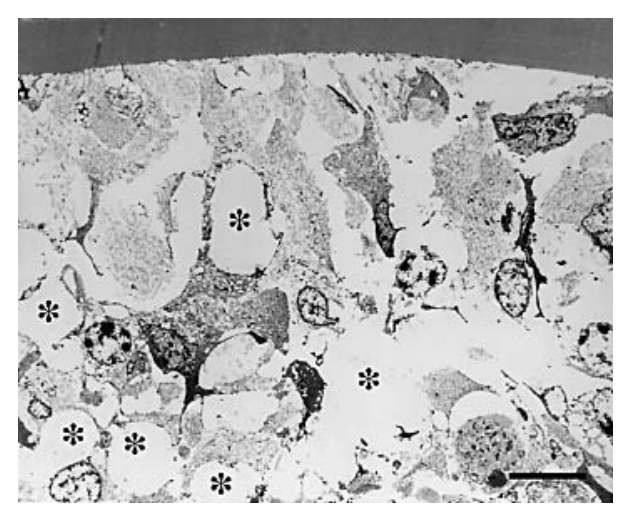

Figure 5 Ultrastructure of tissue newly formed on the central region of the posterior surface of the residual anterior capsule at month 12 . Fibroblast like presumed lens epithelial cells and extracellular matrix accumulation are observed in the specimen with silicone oil tamponade. In the specimen with silicone oil tamponade, many vacuole like structures-suggesting the presence of emulsified silicone oil-were observed among cells (asterisks). Bar: $6 \mu \mathrm{m}$. 
of fibrous components with the bundled characteristic of collagen (fig 3C).

\section{Immunohistochemistry}

Although light and electron microscopy showed the presence of presumed lens cells with a fibroblastic appearance and extracellular matrix accumulation, such morphological observations were not able to reveal the nature of these components. Immunohistochemistry revealed findings similar to those in previous reports ${ }^{29-40}$ : the presence of type IV collagen in the capsule and vimentin positive lens epithelial cells. Lens epithelial cells were negative for type I collagen and cellular fibronectin. The specimens at week 3, with extracellular matrix accumulated on the central posterior surface of the remaining capsule, were labelled with antibodies against collagen types I and IV, cellular fibronectin, and osteopontin (data not shown). Presumed lens cells of a fibroblastic appearance were labelled with the antibodies against vimentin. Cells positive for $\alpha$ smooth muscle actin were also seen as previously reported ${ }^{29-40}$ (data not shown).

\section{Histology of healing capsule with silicone oil tamponade}

Haematoxylin and eosin staining showed similar histological findings: Sommerring's ring was also seen as for cases without silicone oil tamponade (fig 4A). The accumulation of matrix and distribution of fibroblast like presumed lens cells were observed on the posterior surface of the residual anterior capsule. Vacuole like structures were seen amid the matrix (fig 4B).

\section{Ultrastructural examination}

Ultrastructural observation also showed similar histological findings: accumulation of matrix and distribution of fibroblast like presumed lens cells on the posterior surface of the residual anterior capsule (fig 5). Many vacuole like spaces were observed among the accumulation of cells and matrix (fig 5).

\section{Immunohistochemistry}

Immunohistochemistry detected collagen types I, III, and V and cellular fibronectin similar to the specimens without silicone oil tamponade (not illustrated).

\section{DISCUSSION}

In the present study, presumed lens epithelial cells of a fibroblastic appearance and accumulation of extracellular matrix-that is, collagen types I and IV, cellular fibronectin, and osteopontin-were observed on the posterior surface of the residual anterior capsule in eyes following PPL and vitrectomy. Fibroblast like lens cells were observed expressing $\alpha$ smooth muscle actin. The histological findings are similar to those of capsular opacification following cataract extraction and implantation of an intraocular lens. ${ }^{29-40}$ Lens epithelial cells on the residual anterior capsule were exposed to aqueous humour, similar to those following cataract surgery, because the vitreous cavity was replaced by the aqueous humour after removal of the vitreous body. Thus, the cells were considered to be uninfluenced by the growth factors originally contained in the vitreous humour. More interestingly, in eyes with silicone oil tamponade, light and transmission electron microscopies revealed the presence of many vacuoles of presumed emulsified silicone oil amid extracellular matrix accumulation. The deposition of emulsified silicone oil in the iris, ciliary body, and retina tissue has been reported. ${ }^{41}$ Deposition of perfluorodecarine in lens capsular tissue has also been reported. ${ }^{42}$ In the present study, we did not observe emulsified silicone oil engulfed by macrophages, but found that oil droplets were there among presumed lens epithelial cells. It is likely that lens epithelial cells attaching to oil droplets might be stimulated to express many wound healing related molecules including extracellular matrix components. The deposition of emulsified silicone oil droplets may potentially enhance opacification of residual anterior capsule after PPL by both oil deposition and subsequent activation of lens epithelial cells. Further detailed study is needed to examine the effect on lens epithelial cells of exposure to emulsified silicone oil droplets.

\section{Authors' affiliations}

T Miyamoto, S Saika, Y Okada, Y Ohnishi, Department of

Ophthalmology, Wakayama Medical University, Wakayama, Japan

A Yamanaka, Department of Ophthalmology and Kobe Kaisei Hospital, Kobe, Hyogo, Japan

Commercial interest for all authors: none.

Presented by $\operatorname{Dr}$ Miyamoto in part at the annual meeting of the Association for Research in Vision and Ophthalmology, Fort Lauderdale, Florida, USA (May 1998, 1999, and 2001).

\section{REFERENCES}

1 Bhende M, Agraharam SG, Gopal L, et al. Ultrasound biomicroscopy of sclerotomy sites after pars plana vitrectomy for diabetic vitreous hemorrhage. Ophthalmology 2000;107:1729-36.

2 Mato OL. Phacoemulsification and vitrectomy. J Cataract Refract Surg 2000;26:631-32.

3 Pinter SM, Sugar A. Phacoemulsification in eyes with past pars plana vitrectomy: case-control study. J Cataract Refract Surg 1999;25:556-61.

4 Honjo M, Ogura Y. Surgical results of pars plana vitrectomy combined with phacoemulsification and intraocular lens implantation for complications of proliferative diabetic retinopathy. Ophthalmic Surg Lasers 1998;29:99-105.

5 Blankenship GW, Flynn HW Jr, Kokame GT. Posterior chamber intraocular lens insertion during pars plana lensectomy and vitrectomy for complications of proliferative diabetic retinopathy. Am J Ophthalmol 1989;108:1-5.

6 MacCumber MW, Packo KH, Civantos JM, et al. Preservation of anterior capsule during vitrectomy and lensectomy for retinal detachment with proliferative vitreoretinopathy. Ophthalmology 2002;109:329-33.

7 Ram J, Apple DJ, Peng Q, et al. Update on fixation of rigid and foldable posterior chamber intraocular lenses. Part II: Choosing the correct haptic fixation and intraocular lens design to help eradicate posterior capsule opacification. Ophthalmology 1999;106:891-900.

8 Nishi O, Nishi K, Wickstrom K. Preventing lens epithelial cell migration using intraocular lenses with sharp rectangular edges. J Cataract Refract Surg 2000;26:1543-9

9 Mamalis N, Crandall AS, Linebarger E, et al. Effect of intraocular lens size on posterior capsule opacification after phacoemulsification. J Cataract Refract Surg 1995;21:99-102.

10 Mitamura Y, Yamamoto S, Yamazaki S. Corneal endothelial cell loss in eyes undergoing lensectomy with and without anterior lens capsule removal combined with pars plana vitrectomy and gas tamponade. Retina 2000;20:59-62.

11 Gonverse M. Temporary use of intraocular silicone oil in the treatment of detachment with massive periretinal proliferation. Primary report. Ophthalmologica 1982;184:210-18.

12 Chang S, Lincoff HA, Coleman DJ, et al. Perfluorocarbon gases in vitreous surgery. Ophthalmology 1985;92:651-56.

13 Fisher YL, Shakin JL, Slakter JS, et al. Perfluoropropane gas, modified panretinal photocoagulation, and vitrectomy in the management of severe proliferative vitreoretinopathy. Arch Ophthalmol 1988;106:1255-60.

14 Killey FP, Edelhauser HF, Aaberg TA. Intraocular fluid dynamics. Measurements following vitrectomy and intraocular sulfur hexafluoride administration. Arch Ophthalmol 1980;98:1448-52.

15 Bourgeois JE, Machemer R. Results of sulfur hexafluoride gas in vitreous surgery. Am J Ophthalmol 1983;96:405-7.

16 Stern WH, Johnson RN, Irvine AR, et al. Extended retinal tamponade in the treatment of retinal detachment with proliferative vitreoretinopathy. Br J Ophthalmol 1986;70:911-17.

17 Ress TD, Ballantyne DL Jr, Seideman I, et al. Visceral response to subcutaneous and intraperitoneal injections of silicone in mice. Plast Reconstr Surg 1967;39:2-10.

18 Ben-Hur N, Ballantyne DL Jr, Ress TD, et al. Local and systemic effect of dimethilpolysiloxane fluid in mice. Plast Reconstr Surg 1967;39:423-6.

19 Hardt NS, Emery JA, Steinbach BG, et al. Cellular transport of silicone from breast protesis. Int J Ocup Med Toxicol 1995;4:127-34.

20 Amino K, Tanihara H, Gao RL, et al. Silicone oil in the anterior chamber. Graefe's Arch Clin Exp Ophthalmol 1989;227:106-9.

21 Burk LL, Shields $M B$, Proia $A D$, et al. Intraocular pressure following intravitreal silicone oil injection. Ophthalmic Surg 1988;19:565-69.

22 Nguyen QH, Lloyd MA, Hever DK, et al. Incidence and management of glaucoma after intravitreal silicone oil injection for complicated retinal detachments. Ophthalmology 1992;99:1520-6. 
23 Valone J Jr, McCarthy M. Emulsified anterior chamber silicone oil and glaucoma. Ophthalmology 1994;101:1908-12.

24 Saika S, Miyamoto T, Tanaka T, et al. Histopathology of anterior lens capsules in vitrectomized eyes with tamponade by silicone oil. J Cataract Refract Surg 2002;28:376-8.

25 Ohmi S, Uenoyama K. Experimental evaluation of posterior capsule opacification and intraocular lens decentration: comparison of intraocular lenses of $12.5 \mathrm{~mm}$ and $14.0 \mathrm{~mm}$ diameter. J Cataract Refract Surg 1993; 19:348-51.

26 Apple DJ, Lim ES, Morgan RC, et al. Preparation and study of human eyes obtained postmortem with the Miyake posterior photographic technique. Ophthalmology 1990;97:810-16.

27 Saika S, Ohmi S, Tanaka S, et al. Light and scanning electron microscopy of rabbit lens capsules with intraocular lenses. J Cataract Refract Surg 1997;23:787-94

28 Saika S, Kobata S, Hashizume N, et al. Epithelial basement membrane in alkali-burned corneas in rats. Immunohistochemical study. Cornea 1993; 12:383-90.

29 Werner L, Pandey SK, Escobar-Gomez M, et al. Anterior capsule opacification: a histopathological study comparing different IOL styles. Ophthalmology 2000;107:463-71.

30 McDonnel PJ, Zarbin MA, Green WR. Posterior capsule opacification in pseudophakic eyes. Ophthalmology 1983;90:1548-53.

31 Kappelhof JP, Vrensen GF. The pathology of after-cataract. A minireview. Acta Ophthalmol Suppl 1992;205:13-24.

32 Apple DJ, Solomon KD, Tetz MR, et al. Posterior capsule opacification. Surv Ophthalmol 1992;37:73-116.
33 Saika S, Ohmi S, Kanagawa R, et al. Outgrowth of lens epithelial cells and matrix formation on intraocular lenses in rabbit eyes. J Cataract Refract Surg 1996;22:835-40

34 Saika S, Tanaka S, Ohmi S, et al. Deposition of extracellular matrix on intraocular lenses in rabbits: an immunohistochemical and transmission electron microscopic study. Graefe's Arch Clin Exp Opthalmol 1997;235:241-7.

35 Saika S, Ohmi S, Tanaka S, et al. Cell proliferation on the outer anterior capsule surface after extracapsular lens extraction in rabbits. J Cataract Refract Surg 1997;23:1528-31.

36 Saika S, Yamanaka A, Tanaka S, et al. Extracellular matrix on intraocular lenses. Exp Eye Res 1995;61:713-21.

37 Saika S, Kawashima Y, Miyamoto T, et al. Prolyl 4-hydroxylase subunits, $\alpha$-smooth muscle actin and extracellular matrix components on human lens capsules with lens implants. Exp Eye Res 1998;66:283-94.

38 Saika S, Miyamoto T, Kimura M, et al. Degenerated lens epithelial cells in rabbit and human eyes after intraocular lens implantation. $J$ Cataract Refract Surg 1998;24:1396-8.

39 Saika S, Miyamoto T, Tanaka S, et al. Response of lens epithelial cells to injury: role of lumican in epithelial-mesenchymal transition. Invest Ophthalmol Vis Sci 2003;44:2094-102

40 Saika S, Miyamoto T, Ishida I, et al. Osteopontin: a component of matrix in capsular opacification and subcapsular cataract. Invest Ophthalmol Vis Sci 2003:44:1622-8.

41 Shaikh S, Egbert PR, Goldblum RS, et al. Granulomatous local cell reaction to intravitreal silicone. Arch Ophthalmol 2000;118:1133-4.

42 Singh J, Ramaesh K, Wharton SB, et al. Perfluorodecalin-induced intravitreal inflammation. Retina $2001 ; 21: 247-51$. 